\title{
A Study of Business Students' Attitudes in Saudi Arabia: Generation C, Islamic Values, and Westernised Educational Video
}

\section{G Martin Izzo' ${ }^{1}$ and Shaza W Ezzi ${ }^{*}$}

${ }^{1}$ Fulbright Scholar, Visiting Associate Professor, Department of Marketing, King Abdulaziz University, Saudi Arabia

${ }^{2}$ Assistant Professor, Department of Marketing, King Abdulaziz University, Saudi Arabia

\begin{abstract}
The present study investigated the relationships between Saudi Arabian college students and the "connected" Generation C, their use of small mobile devices to access video, video usage in the classroom, and behavioral variables like the willingness to seek and share video outside the classroom. Additionally, the study explored the relationship between Saudi Arabian students' attitudes about classroom learning through the use of Westernised videos where the content was presented in situations not in keeping with strict Islamic laws and traditions. Four research questions were generated and data was gathered using the Video Attitude Survey-a five point Likert scale instrument. The data was collected from college students $(\mathrm{N}=139)$ enrolled in business school classes at large public university. Descriptive statistics, Pearson correlations and selected Chi square analyses were conducted on the data. Frequency distributions were calculated to show the variables of interest for each research question, and then presented in concurrent tables.

The findings indicate that Saudi Arabian students living in a strict Islamic society still see themselves as part of the worldwide Generation C. That they use mobile devices to download and distribute video, more for social networking and trend-pacing than for news services. That their strong ties to Islamic tradition have a weak yet significant influence on learning from Westernised educational video. The study's most promising findings were the positive relationships between students' attitudes toward learning through educational video, improving their English speaking ability, and gaining a greater understanding of multi-cultural issues and differences.
\end{abstract}

Keywords: Saudi Arabia; Generation C; Islamic values; Educational video

\section{Introduction}

The present study investigated attitudes about the "connected" generation, video usage, and in particular Westernised educational video of business students at a large public university in Saudi Arabia. The social mores are different in Saudi Arabia, and the Islamicinfluenced social structure is considered far more strict, even when compared to its Arab neighbors like Kuwait and Oman [1]. While Saudi Arabian college students based on age cohort are no less a part of the "connected" generation than their counterparts the world over their attitude toward membership in this group is relatively unknown $[2,3]$.

Labeled by Nielsen, often shortened to Gen C by various media, Generation C (where C stands for connected) is a group so connected by mobile devices that it leads all other groups in the use of online videos, networking, blog sites and the ownership of tablets and smartphones $[2,4,5]$. As a rule, Generation $\mathrm{C}$ were born after 1990 and lived their adolescent years after 2000. In the developed world, Generation C encompasses everyone in this age group; in the BRIC countries (Brazil, Russia, India, and China), they are primarily urban and suburban [4]. The importance to marketers is that by 2020 Generation C will constitute the largest single cohort of consumers worldwide [6]. Additionally, when it comes to shopping and buying decisions, 85 percent of Generation $C$ relies on peer input and approval [6]. Decision-making has become a team sport, where practically every product or service considered for purchase is reviewed, rated, and shared. "Marketing successfully becomes all about "talking to the community, not the individual" and creating a conversation for the swarm to run with" suggests Dan Pankraz, Youth Strategist, DDB Sydney [4].Thus, successful brand marketing with Generation C means getting into "tribal conversations" that are happening around and across different tribes, and connecting brand names, products and services with interesting ideas, cultural objects, causes and movements.

While their use of handheld technology and Internet prowess may be documented, little is known about the attitudes of Generation C toward video use in the classroom. The ways in which Saudi students embrace Westernised video in classrooms may provide insights to marketers as to how they will relate to similarly-styled advertising messages from commercial sources. Further, the present study is the first of its kind to actually go into the classrooms of Saudi Arabian students to find out how they associate with being part of Generation C, and what they think about Westernised educational video. Thus, understanding the attitudes of Saudi Arabian business students contributes to the overall research of Generation C, and adds information important to marketers everywhere.

\section{Purpose of Study: the who, what, why and where for the study}

Who

Following in the digital footprints of the millennials, Generation $\mathrm{C}$ - with the C standing for "connected" - is a term coined by Nielsen, a global leader in measurement and information, to describe young adults between the ages of 18 and 34 who lead a mainly digital

*Corresponding author: Shaza W Ezzi, Assistant Professor, Department of Marketing, King Abdulaziz University, Jeddah, Saudi Arabia. PO Box 42623, 21551, E-mail: shazaezzi466@gmail.com

Received July 23, 2013; Accepted August 30, 2013; Published Sptember 02 2013

Citation: Citation: Izzo G M, Ezzi S W (2013) A Study of Business Students Attitudes in Saudi Arabia: Generation C, Islamic Values, and Westernised Educational Video. J Bus Fin Aff 2:111 doi:10.4172/2167-0234.1000111

Copyright: (c) 2013 Izzo GM \& Ezzi SW. This is an open-access article distributed under the terms of the Creative Commons Attribution License, which permits unrestricted use, distribution, and reproduction in any medium, provided the original author and source are credited. 
lifestyle. Although making up just 23 percent of the U.S. population, and an untold number worldwide, this group leads all other groups in their use of online videos, networking, blog sites and in owning tablets and smartphones [4]. As a rule, they were born after 1990 and lived their adolescent years after 2000. In the developed world, Generation C encompasses practically everyone in this age group [6]. By 2020, Generation $\mathrm{C}$ will make up 40 percent of the population in the U.S., Europe, and the BRIC countries [7].

With a median age of only 26 Saudi Arabia has a comparatively young population. According to [8] report, Saudi Arabia's population $15-24$ years is $19.6 \%$ and $25-54$ years is $44.8 \%$. By contrast, population statistics in these ranges for two of Saudi Arabia's trading partners are: Turkey $17 \%$ and $42 \%$, and United Kingdom $13 \%$ and $41 \%$.For Saudi Arabia, these two age groups comprise about $64.4 \%$ of population, and slightly overlap the Generation C 18-34 range. However, this presents the statistic of a sizable, young demographic, and adds support for studying the "connected" behaviors of Generation C, as they represent a large portion of Saudi Arabia's population. Marketers and researchers call Generation C - connected, communicating, content-centric, computerized, community-oriented, and seemingly always clicking their personal digital devices [6]. Researchers needed to identify this group so that it could be accounted for in market research. Marketers, on the other hand, needed to update their thinking and revise their marketing plans and sales strategies to focus on this connected generations' buying power and affinity for group decision-making. Determining how pervasive this new Generation $\mathrm{C}$ is in light of other world cultures, and in particular in the strict social structure of Saudi Arabia, is a timely and relevant research endeavor $[2,3,5]$.

\section{What}

While Generation C leads all other groups in its use of online videos and social networking, little is known about how this group feels about the use of educational video in the classroom. Much research has investigated the effects of television and video on children, from toddlers, to pre-school and as young adolescents, very little research has been published about young adults and college students [e.g. 9, 12]. Additionally, much of the research that involves evaluating the educational effects of video is proprietary in nature, and as a result, unpublished $[13,14]$. However, researchers suggest that more research of educational aspects of television and video on different aged populations is needed [e.g. 10,12]. The present study helps to address this need by investigating college students. Since video, particularly viral video is a major part of the communications arsenal of Generation $\mathrm{C}$, it is important to understand how this group feels about educational video used in the courses they study. Given the proclivity of this group toward social networking and participating in on-line group decision making, video in the classroom has the potential to become an attractive learning tool. Generation $\mathrm{C}$ already uses video as one of its main entertainment outlets information and fact-finding sources, so it may be reasonable to expect this group to embrace the use of education video.

However, the same may not hold true in Saudi Arabia. While educational videos are one of the most prolific modern educational methods being used in highly-developed countries, the same is not true in developing nations [15]. Prior research examined Saudi Arabian university students' cultural response to technological change by investigating acceptance of Internet banking [16]. Examining how firm contexts that are influenced by Islamic values such as in Saudi Arabia contrast with more Westernised business practices may shape business students' understanding of cross-cultural organizational mechanisms and processes. Using depth interviews with Saudi toplevel managers and expatriate, customer-facing sales and marketing personnel [17] found harmony among firms using a formal Saudi top-down managerial structure, a slightly different model from the more interactive approach practiced at many Western firms. Culture does matter, and accordingly, the different aspects of Islamic values and Saudi tradition may influence student's acceptance as members of Generation C and the use of Westernised educational videos in the classroom.

\section{Why}

Beyond the challenges discussed above facing marketers and advertisers bootstrapping to understand Generation C, destined to be the largest consumer group on the planet by the year 2020, employers will have to deal with the "connectedness" of Generation C. "As the world becomes increasingly global and mobile, employers can benefit from workers who are in tune with the latest technology and are adept at communicating through the latest devices and collaborating with people all over the world" [2, p.1]. The connectedness of Generation $\mathrm{C}$ can empower and align workforces to levels never achieved before, creating on-line real-time collaboration through digitalized technology and with enhanced mobility [5,2]. Generation $\mathrm{C}$ members are experts with forming groups or tribes to share information, digesting large amounts of information quickly, and are resistant to processes and concepts that are not optimized for these proficiencies. For example, members of Generation C are much more comfortable seeking connections with other audiences and using their social networking skills to find solutions to well-defined problems [2]. This will be a key strength as they enter the workforces of today's interconnected business environments. However, in order to leverage the power of Generation C, businesses and other employers will be required to learn more about them in order to connect with them in their totally plugged-in lifestyles.

\section{Where}

While educational videos have been used in most education institutions of highly-developed countries, usage is still in its early stages in the developing countries [15]. This is especially true for conservative Islamic countries such as Saudi Arabia [e.g. 18,20]. Therefore, this research was conducted in Saudi Arabia because of its unique Islamic culture that influences practically every aspect of people's daily lives and behaviors. Gender separation, one of the most well-known and unique features or rules in Saudi culture, has influenced peoples' attitudes negatively toward the liberal lifestyles practiced in Westernised cultures $[19,21,22]$. For example, Saudi men and women are not permitted to attend public events together and are segregated in the work place. The separation concept, which originated from Islamic law has become a social tradition $[19,21,22]$.Thus, further investigation is needed to determine if video use in Islamic cultures is appropriate in general. Saudi Arabia, the acknowledged heartland of Islam, presents a greater challenge as one of the most socially conservative Muslim countries in the Arab region [18,20]. Moreover, the city of Jeddah where the study took place is considered the center of Muslim religious thought, and gateway to Islam's two holy cities, Madinah (Medina) and Makkah (Mecca) [22]. 
The present study was conducted to investigate the attitudes of college students toward Generation $\mathrm{C}$, and the use of on-line and Westernised educational videos. The social mores of Saudi Arabia are different, and Saudi Arabia's interpretation of Islam creates a social structure that is considered more strict, even when compared with other Arabic and Islamic countries. Would these factors have an impact on whether or not Saudi students see themselves as members of the "connected" Generation C? Do Islamic beliefs and Saudi Arabia's stricter social fabric affect Saudi Arabian college students' using online video? How do Saudi Arabian college students perceive the use of educational video? These inquiries led to the following research questions:

Research Question (RQ) 1.

Do Saudi Arabian college students from a strict Islamic culture see themselves as part of the modern day Generation C?

Research Question (RQ) 2 .

Do Saudi Arabian college students use on-line video as a source of information used in their daily lives?

Research Question (RQ) 3.

Are Saudi Arabian college students from a strict Islamic culture negativelyaffected by videos portraying Westernized beliefs and culture?

Research Question (RQ) 4. How do Saudi Arabian college students perceive the use of educational video in the classroom?

\section{Materials and Methods}

\section{Sample}

A judgment-type sampling procedure suitable for the present research objectives was used to collect data for the study [23]. Surveys were administered to 147 undergraduate male and female students. Due to unscorable responses 8 surveys were removed leaving 139 usable surveys. The respondents included in the study were from the student body of the business faculty at a large public university in Saudi Arabia. All students were enrolled in International business courses (classes where the subject language is taught in English). The rationale for using college students was that they fit well with the profile description of the study population. Specifically, the respondents in the study were age-appropriate, college students enrolled in International business courses where the classes are taught in English. In addition, the authors felt that students would be interested participants in the study by the nature of the subject of the research.

An important consideration was the issue of sufficiency in the number of observations to meet the purposes of the study, measuring attitudes. According to completed studies that investigated similar attitude phenomena, there should be at least 103 observations [24-26]. Thus, a sample size of 139 was considered sufficient for the purposes of the study.

\section{Instrument}

Video Attitudes Survey (VAS) [27] used the Computer Attitude Scale (CAS) in a study to measure students' computer attitudes and found improvement in respondents' feelings of comfort in using computers after completion of the activities. Video Attitude Survey (VAS) was adapted and modified from the attitudinal constructs of the CAS instrument to make it more applicable to the present investigation, measuring students' attitudes while reflecting the differences in technology between computers and video. The students were advised that the survey was assessing their beliefs, feelings, and behaviors in relation to using commercial video services, marketing subject educational video use in the classroom, and that there were no wrong or right answers. Survey respondents were assured of their anonymity with respect to filling out the surveys.

\section{Data Analysis}

The four research questions listed above are the basis for the analysis in the study. Some statistical procedures were used to accomplish the purposes of the study. First, descriptive statistics were calculated to present the characteristics of the sample and frequencies of certain categorical items. Second, Pearson correlations were computed to examine the relationships among the variables. Data was collected using the VAS, and scored on a five-point Likert scale where; $1=$ 'Strongly Disagree'; 2 = 'Disagree'; 3 = 'Neither agree nor disagree'; 4 = 'Agree'; and $5=$ 'Strongly Agree'. To aid in the discussion of each of the four research questions frequency tables were calculated and concurrently placed for the variables of interest (Table 1).

Finally, Chi-square analyses were conducted on selected variables to explore the potential relationships between Islamic values and video usage by gender to identify possible predictors of attitudes toward video usage by the connected generation (Table 2).

\section{Results}

\section{Research Question RQ1}

Table 1 presents the descriptive statistics of the basic characteristics of the sample and frequencies of several categorical variables. The first research question can be addressed with summary statistics contained in Table 1 Regarding RQ1 approximately $93 \%$ of student respondents see themselves members of Generation C. Table 2 shows Variable VC7-18 was strongly correlated with behavioral variable VU8-10 downloading video to keep up with latest trends and information $(\mathrm{r}=.37$, $\mathrm{P}<.01)$. Providing additional support, in Table 3, frequency distributions for VC7-18 shows that,of those surveyed, approximately $88 \%$ agree with the statement, $62 \%$ 'Strongly Agree' and $26 \%$ 'Agree. This belief has scored a high mean value, $4.45 / 5$, representing a positive attitude of respondents toward the importance of Smartphones in their "connected" lives. These findings support that Saudi Arabian students surveyed do see themselves as part of Generation C (Table 3).

\section{Research Question RQ2}

RQ2 pertains to how Saudi Arabian college students use on-line video as a source of personal information and in their classes. Table 4 presents frequency distributions for usage variables. The overall results in Table 4 indicate that respondents have positive attitudes toward watching and using on-line videos as a source of information. Examination of responses to specific statements reveals that respondents believe that using on-line videos is a source of information for their education, and to keep up with the latest information and trends as a part of the Generation C's communications. In addition, VU1-1 watching videos from the Internet in general scored the highest mean, 4.13, indicating that Generation $\mathrm{C}$ depends on on-line videos as a source of information and a way to be connected with other members from their generation. Moreover, the correlation coefficient test found that there are moderate strength but significant relationships between some of the study variables. For example, the relationships between VU1-1 and VU8-10 ( $r=.-37, \mathrm{P}<0.01)$; VU3-7 and VU8-10 $(\mathrm{r}=.33, \mathrm{P}<$ .01 , and VU4-13 and VU8-10 $(\mathrm{r}=.41, \mathrm{P}<.01$ all were significant. VU22 has only significant relationship with VU4-13(r=.34, $\mathrm{P}<.01$. These results highlight that respondents who like watching videos from the 
Citation: Citation: Izzo G M, Ezzi S W (2013) A Study of Business Students' Attitudes in Saudi Arabia: Generation C, Islamic Values, and Westernised Educational Video. JBus Fin Aff 2:111 doi:10.4172/2167-0234.1000111

Page 4 of 6

\begin{tabular}{|c|c|c|c|c|c|c|c|c|}
\hline Gender & Frequency & Percent & Major & Frequency & Percent & Course & Frequency & Percent \\
\hline Female & 72 & 51.8 & Business Admin. & 19 & 13.8 & Accounting & 5 & 3.6 \\
\hline Male & 67 & 48.2 & Marketing & 51 & 36.7 & Finance & 18 & 13 \\
\hline Total & 139 & 100.0 & HR & 11 & 7.9 & HR & 8 & 5.8 \\
\hline Age & Frequency & Percent & Finance & 6 & 4.3 & Management & 9 & 6.5 \\
\hline 19 & 5 & 3.6 & MIS & 14 & 10.0 & Principles of Marketing & 48 & 34.6 \\
\hline 20 & 23 & 16.5 & Accounting & 22 & 15.8 & Consumer Behavior & 13 & 9.4 \\
\hline 21 & 61 & 43.9 & Other & 16 & 11.5 & Marketing Communication & 11 & 7.9 \\
\hline 22 & 34 & 24.5 & Total & 139 & 100.0 & Sales & 17 & 12.3 \\
\hline 23 & 11 & 7.9 & Connected Generation & Frequency & Percent & E-marketing & 9 & 6.5 \\
\hline 24 & 5 & 3.6 & Yes & 129 & 92.8 & & & \\
\hline Total & 139 & 100.0 & No & 10 & 7.2 & & & \\
\hline & & & Total & 139 & 100.0 & Total & 139 & 100.0 \\
\hline
\end{tabular}

Table 1: Descriptive Statistics Analysis.

\begin{tabular}{|c|c|c|c|c|c|c|c|c|c|c|c|c|c|c|c|}
\hline Variables & VU1-1 & VU2-2 & VU3-7 & VU4-13 & VC1-9 & VC2-19 & VC3-14 & VL1-3 & VL2-8 & VL3-11 & VL4-17 & VC5-12 & VU8-10 & VC7-18 & \\
\hline VU1-1 & & - & $.262^{* *}$ & $.240^{* *}$ & $.234^{* *}$ & .031 & -.004 & .033 & .059 & $.176^{*}$ & .026 & .036 & $.231^{* *}$ & $.372^{* *}$ & $.171^{*}$ \\
\hline VU2-2 & & & - & .051 & $.333^{* *}$ & $.167^{*}$ & .121 & .102 & $.498^{* *}$ & $.281^{* *}$ & $.341^{* *}$ & $.257^{* *}$ & $.195^{\star}$ & .131 & .166 \\
\hline VU3-7 & & & & - & $.285^{\star *}$ & -.048 & .068 & .026 & .111 & .092 & .087 & .070 & .073 & $.331^{* *}$ & $.240^{* *}$ \\
\hline VU4-13 & & & & & - & .137 & .067 & .061 & $.394^{* *}$ & $.199^{\star}$ & $.359^{* *}$ & $.304^{* *}$ & .136 & $.408^{* *}$ & $.321^{* *}$ \\
\hline VC1-9 & & & & & & - & $-.312^{* *}$ & $.236^{\star \star}$ & $.256^{* *}$ & .161 & $.257^{* *}$ & $.211^{*}$ & .075 & $.261^{* *}$ & .106 \\
\hline VC2-19 & & & & & & & - & $-.208^{*}$ & .110 & -.039 & -.126 & -.021 & -.160 & -.123 & -.025 \\
\hline VC3-14 & & & & & & & & - & .094 & .078 & .043 & -.043 & .091 & .022 & .123 \\
\hline VL1-3 & & & & & & & & & - & $.195^{*}$ & $.386^{* *}$ & $.243^{* *}$ & .118 & $.238^{* *}$ & $.174^{*}$ \\
\hline VL2-8 & & & & & & & & & & - & .111 & $.321^{* *}$ & $.573^{* *}$ & $.300^{* *}$ & $.331^{* *}$ \\
\hline VL3-11 & & & & & & & & & & & - & $.619^{* *}$ & $.206^{*}$ & .164 & .139 \\
\hline VL4-17 & & & & & & & & & & & & - & $.430^{* *}$ & .164 & $.229^{\star *}$ \\
\hline VC5-12 & & & & & & & & & & & & & - & $.320^{* *}$ & $.366^{\star *}$ \\
\hline VU8-10 & & & & & & & & & & & & & & - & $.369^{* *}$ \\
\hline VC7-18 & & & & & & & & & & & & & & & - \\
\hline$N$ & $\mathrm{~N}$ & 139 & 139 & 139 & 139 & 139 & 139 & 139 & 139 & 139 & 139 & 139 & 139 & 139 & 139 \\
\hline
\end{tabular}

${ }^{* *}$ Correlation is significant at the 0.01 level (2-tailed)

${ }^{*}$ Correlation is significant at the 0.05 level (2-tailed)

Table 2: Pearson Correlations for Study Variables.

Variable - Description

VC7-18: I believe that small mobile device and Smartphones have made accessing video easier for my generation

\begin{tabular}{|c|c|c|c|c|c|c|c|}
\hline 1 & 2 & 3 & 4 & 5 & Total & Mean & SD \\
\hline 1 & 5 & 11 & 36 & 86 & 139 & 4.4 & 0.84 \\
$0.7 \%$ & $3.6 \%$ & $7.9 \%$ & $25.9 \%$ & $61.9 \%$ & $100 \%$ & 5 & 4 \\
\hline
\end{tabular}

Table 3: Mobile Devices and Video Usage.

Internet for their daily life needs are more likely to use video as source of information for educational purposes (Table 4).

\section{Research Question RQ3}

This question asks if Saudi Arabian college students' attitudes toward videos are negatively affected where the material may not be in keeping with strict Islamic values. From Table 2, the correlations between the 3 observed variables is if nothing else, interesting. VC219 negatively correlates $(\mathrm{r}=.-31, \mathrm{P}<.01)(\mathrm{r}=.21, \mathrm{P}<.01)$, respectively, with variables VC1-9 and VC3-14 which correlate positively $(\mathrm{r}=.24, \mathrm{P}$ $<.01)$. While none of these relationships bordering between weak and moderate are particularly strong, the relationship may expose a bias. Chi-square analyses revealed that in terms of gender there was only a significant male difference on VC2-19 (13.84, $p=.008$, expected value $8.19, \mathrm{~N}=139$ ), suggesting that male students seem more offended than females by videos containing materials not in keeping with Islamic traditions. In Table 5, the frequency distributions show heavy midpoint or neutral response counts ranging from 25 to $30 \%$ which may mask the true meaning of the respondents, and contribute to the weak findings.
However, if the neutral group's answers truly signal disinterest, then it might be quite reasonable to include them as unaffected, and thus increase positive responses. To summarize the data shows weak to moderate negatively affected correlation coefficients and a Chi-square of males over females on variable VC2-19. Given these findings it becomes difficult to suggest that students' attitudes toward videos with Westernized content are negatively affected by strict Islamic traditions. At the same time, it becomes difficult to say overall whether or not Saudi Arabian college students have a positive view of the educational benefits of Westernised videos. Clearly more research is needed with respect to these variables (Table 5).

\section{Research Question RQ4}

This question analyzed the relationships of Saudi Arabian college students' perceptions of and behavior to seek learning through educational video in the classroom. Four of the five variables in Table 6 clearly show that students perceived value of and a willingness to seek video in their classes. For classes in both Arabic and English, the summed percentages that indicated 'Strongly Agree' and 'Agree' ranges 
Citation: Citation: Izzo G M, Ezzi S W (2013) A Study of Business Students' Attitudes in Saudi Arabia: Generation C, Islamic Values, and Westernised Educational Video. JBus Fin Aff 2:111 doi:10.4172/2167-0234.1000111

Page 5 of 6

from $55 \%$ for VL1-3 up to $84 \%$ for VL2-8. Consequently the summations for those who 'Strongly Disagree' and 'Disagree' were particularly low ranging from just $4 \%$ for VC5-12 to a high of $19 \%$. VL3-11 was the only variable to break above trend, showing only $40 \%$ for those in agreement with $28 \%$ in disagreement. However, since this variable concerned behavior to seek access to video outside the classroom for classes taught in Arabic this result is somewhat understandable. From Table 3, the correlation between behavior seeking VL3-11 and VL4-17 $(\mathrm{r}=.-62, \mathrm{P}<.01)$ was strong and significant. The interactions between VL4-17 and VC5-12 ( $\mathrm{r}=.-43, \mathrm{P}<.01)$ and VL4-17 and VL2-8 ( $\mathrm{r}=.-57$, $\mathrm{P}<.01)$ were both strong. These findings clearly point to a positive relationship between students taking classes taught in English and learning from educational videos. Overall students value educational video in the classroom, and are willing to seek them to increase their learning (Table 6).

\section{Discussion and Conclusions}

This study explored some of the possible relationships among the attitudes of Saudi Arabian college students toward Generation C and Westernised educational video. In doing so, four fundamental research questions were presented, analyzed, and discussed. The findings in RQ1 reveal that Saudi Arabian college students whose environment is characterized by strict Islamic traditions include themselves as members of the Generation C. In RQ2 these college students generally responded favorably toward the use of on-line video indicating a greater preference for social communication and popular content with less interest in major news information. These findings are completely consistent with the networking goals of Generation $\mathrm{C}$ members. With respect to RQ3 measuring the interaction between strict Islamic traditions and watching Westernized educational videos the results were not as clear. While most Saudi Arabian college students see moderate value in watching and learning from Westernized educational videos, correlations showed a weak but significant number (Males) were negatively influenced by their strong Islamic traditions. This indicates that while Saudi Arabian college students see themselves as being part of the Generation C, their beliefs are also influenced by Islamic culture. This particular finding may be important to advertisers and marketers trying to develop messages to reach out to this group of Saudi Arabians. RQ4 analyzed the interactions between Saudi Arabian college students' perceptions of and behavior toward seeking learning through educational video in the classroom. With exception of courses taught in Arabic, Saudi Arabian college students highly value educational video in the classroom, and are willing to seek videos outside to increase their in-class learning. The strongest and most promising findings of the study were the relationships between students' attitudes toward learning through educational video, improving their English speaking ability, and gaining greater understanding of multi-cultural issues and differences. Again, these findings on Saudi Arabian college students' attitudes toward educational video, and their use of small mobile devices for finding and sharing information and networking, are totally consistent with being both socially and technologically part of Generation C.

\begin{tabular}{|c|c|c|c|c|c|c|c|c|}
\hline Variable & 1 & 2 & 3 & 4 & 5 & Total & Mean & SD \\
\hline VU1-1: I like watching videos from the Internet & $\begin{array}{c}2 \\
1.4 \%\end{array}$ & $\begin{array}{c}9 \\
6.5 \%\end{array}$ & $\begin{array}{c}16 \\
11.5 \%\end{array}$ & $\begin{array}{c}54 \\
38.9 \%\end{array}$ & $\begin{array}{c}58 \\
41.7 \%\end{array}$ & $\begin{array}{c}139 \\
100 \%\end{array}$ & 4.13 & .954 \\
\hline $\begin{array}{l}\text { VU2-2: I access videos as a source of information in my } \\
\text { present courses }\end{array}$ & $\begin{array}{l}5 \\
3.6 \% \\
\end{array}$ & $\begin{array}{c}21 \\
15.1 \% \\
\end{array}$ & $\begin{array}{c}48 \\
34.6 \%\end{array}$ & $\begin{array}{c}53 \\
38.1 \% \\
\end{array}$ & $\begin{array}{c}12 \\
8.6 \%\end{array}$ & $\begin{array}{c}139 \\
100 \%\end{array}$ & 3.33 & .958 \\
\hline $\begin{array}{l}\text { VU3-7: Videos available through the Internet news services } \\
\text { are a major source of my information }\end{array}$ & $\begin{array}{c}7 \\
5 \%\end{array}$ & $\begin{array}{c}37 \\
26.6 \%\end{array}$ & $\begin{array}{c}47 \\
33.8 \%\end{array}$ & $\begin{array}{c}36 \\
26 \%\end{array}$ & $\begin{array}{c}12 \\
8.6 \%\end{array}$ & $\begin{array}{c}139 \\
100 \%\end{array}$ & 3.06 & 1.03 \\
\hline VU4-13: I send a lot of Internet videos to my friends & $\begin{array}{c}8 \\
5.6 \%\end{array}$ & $\begin{array}{c}31 \\
22.3 \%\end{array}$ & $\begin{array}{c}40 \\
28.8 \%\end{array}$ & $\begin{array}{c}45 \\
32.8 \%\end{array}$ & $\begin{array}{c}15 \\
10.8\end{array}$ & $\begin{array}{c}139 \\
100 \%\end{array}$ & 3.20 & 1.01 \\
\hline $\begin{array}{l}\text { VU8-10: I believe that downloading video to keep up with } \\
\text { the latest information and trends is part of how my genera- } \\
\text { tion communicates }\end{array}$ & $\begin{array}{c}2 \\
1.4 \%\end{array}$ & $\begin{array}{c}11 \\
7.9 \%\end{array}$ & $\begin{array}{c}32 \\
23 \%\end{array}$ & $\begin{array}{c}57 \\
41.1 \%\end{array}$ & $\begin{array}{c}37 \\
26.6 \%\end{array}$ & $\begin{array}{c}139 \\
100 \%\end{array}$ & 3.83 & .960 \\
\hline
\end{tabular}

Table 4: Saudi Arabian Student Usage of On-line Video

Variable - Description

VC1-9: I would not mind watching educational videos assuming the materials do not in-line with the Is lamic culture

VC2-19: I would be offended if some material is presented that is not in keeping with Islamic traditions

VC3-14: I believe watching videos that portray behaviors that are non-Islamic are/can be educational/helpful for learning

\begin{tabular}{|c|r|}
\hline $\mathbf{1}$ & \\
\hline 13 & \\
$9.3 \%$ & 12 \\
\hline 23 & \\
$16.6 \%$ & 17 \\
\hline 37 & \\
$26.6 \%$ & 17 \\
\hline
\end{tabular}

$\mathbf{2}$
18
$12.9 \%$
24
$17.3 \%$
24
$17.3 \%$

\begin{tabular}{|c|}
\hline 3 \\
40 \\
$28.8 \%$ \\
42 \\
$30.2 \%$ \\
\hline 35 \\
$25.2 \%$ \\
\hline
\end{tabular}

\begin{tabular}{|c|}
\hline 4 \\
\hline 44 \\
$31.7 \%$ \\
\hline 33 \\
$23.7 \%$ \\
\hline 32 \\
\hline $23 \%$ \\
\hline
\end{tabular}

\begin{tabular}{c}
$\mathbf{5}$ \\
24 \\
$17.3 \%$ \\
17 \\
$12.2 \%$ \\
11 \\
$7.9 \%$ \\
\hline
\end{tabular}

Total
139
$100 \%$
139
$100 \%$
139
$100 \%$

\begin{tabular}{|c|c|}
\hline Mean & SD \\
\hline 3.35 & 1.184 \\
\hline 2.98 & 1.254 \\
\hline 2.68 & 1.302 \\
\hline
\end{tabular}

Table 5: Islamic Values and Westernized Videos

\begin{tabular}{|c|c|c|c|c|c|c|c|c|}
\hline Variable & 1 & 2 & 3 & 4 & 5 & Total & Mean & SD \\
\hline $\begin{array}{l}\text { VL1-3: I feel that videos will enhance my learning for courses } \\
\text { taught in Arabic }\end{array}$ & $\begin{array}{c}5 \\
3.6 \%\end{array}$ & $\begin{array}{c}21 \\
15.1\end{array}$ & $\begin{array}{c}36 \\
25.9 \%\end{array}$ & $\begin{array}{c}49 \\
35.3 \%\end{array}$ & $\begin{array}{c}28 \\
20.1 \%\end{array}$ & $\begin{array}{c}139 \\
100 \%\end{array}$ & 3.53 & 1.09 \\
\hline $\begin{array}{l}\text { VL2-8: I feel that videos will enhance my learning for courses } \\
\text { taught in English }\end{array}$ & $\begin{array}{c}2 \\
1.4 \%\end{array}$ & $\begin{array}{c}10 \\
7.2 \%\end{array}$ & $\begin{array}{c}11 \\
7.9 \%\end{array}$ & $\begin{array}{c}56 \\
40.3 \%\end{array}$ & $\begin{array}{c}60 \\
43.2 \%\end{array}$ & $\begin{array}{c}139 \\
100 \%\end{array}$ & 4.17 & .952 \\
\hline $\begin{array}{l}\text { VL3-11: I would access on my own time educational videos } \\
\text { for my courses taught in Arabic }\end{array}$ & $\begin{array}{c}7 \\
5 \%\end{array}$ & $\begin{array}{c}32 \\
23 \%\end{array}$ & $\begin{array}{c}44 \\
31.7 \%\end{array}$ & $\begin{array}{c}40 \\
28.8 \%\end{array}$ & $\begin{array}{c}16 \\
11.5 \%\end{array}$ & $\begin{array}{c}139 \\
100 \%\end{array}$ & 3.19 & 1.07 \\
\hline $\begin{array}{l}\text { VL4-17: I would access on my own time educational videos } \\
\text { for my courses taught in English }\end{array}$ & $\begin{array}{c}6 \\
4.3 \%\end{array}$ & $\begin{array}{c}10 \\
7.2 \%\end{array}$ & $\begin{array}{c}34 \\
24.5 \%\end{array}$ & $\begin{array}{c}55 \\
39.6 \%\end{array}$ & $\begin{array}{c}34 \\
24.5 \%\end{array}$ & $\begin{array}{c}139 \\
100 \%\end{array}$ & 3.73 & 1.05 \\
\hline $\begin{array}{l}\text { VC5-12: I believe that watching videos in English will help me } \\
\text { to better understand multi-cultural issues or differences }\end{array}$ & $\begin{array}{c}1 \\
0.7 \%\end{array}$ & $\begin{array}{c}4 \\
2.9 \%\end{array}$ & $\begin{array}{c}18 \\
13 \%\end{array}$ & $\begin{array}{c}53 \\
38.1 \%\end{array}$ & $\begin{array}{c}63 \\
45.3 \%\end{array}$ & $\begin{array}{c}139 \\
100 \%\end{array}$ & 4.24 & .841 \\
\hline
\end{tabular}


Citation: Citation: Izzo G M, Ezzi S W (2013) A Study of Business Students' Attitudes in Saudi Arabia: Generation C, Islamic Values, and Westernised Educational Video. JBus Fin Aff 2:111 doi:10.4172/2167-0234.1000111

Page 6 of 6

\section{Implications}

Tomorrows' college graduates, members of the Generation C, will contribute more than the skills and abilities learned through their college experiences. These constantly connected generation college graduates will also bring the value of their networking skills and technological expertise to the organizations that hire them. Their ability to network and stay connected has the potential to result in organizational productivity. Through their networking collaboration and technological mobility, these Generation C graduates will increasingly help organizations to achieve goals and objectives by creatively solving problems, taking on responsibility, working independently, and collaborating with peers. Accessing, using and sending videos to contacts are just some of the tools in Generation C's vast communications arsenal. Generation C members form their identities by belonging and expressing themselves within "tribes" reflecting the desire to "connect" around interesting ideas, cultural objects, causes and movements. Brands need to get into conversations that are happening within and across tribes. This will give their messages more credibility and attention compared to external sources- by expressing opinions, sharing ideas, observations and thoughts. Their influence depends on what they share and how often they share it.

\section{Limitations and Future Research}

Even though this study explored the relationships and interactions of several groups of variables that surround Generation C's attitudes toward video usage in the classroom, causal relationships were not explored. It is recommended that further studies examine the causal relationships through structural models and experimental designs. Further the study was geographically limited to one university, and only students of the college of business and administration. Future research would benefit from expanding the sample to include students of other college disciplines, and at different colleges. Finally, while this study focused on video usage in general, new research should attempt to focus and document specific educational video initiatives, and to evaluate them in terms of specific educational goals.

\section{Acknowledgements}

The authors wish to recognize Ms. Saga Shaabin, doctoral student, for her assistance in the current research particularly with survey item English-to-Arabic interpretation, some data collection and data entry, and help with preparing the exhibits and word processing.

\section{References}

1. Al-Khatib J, Vitell S, Rexeisen R and Rawwas M (2005) Inter-country differences of consumer ethics in Arab countries. International Business Review 14: 495516

2. Harris I (2013) Connecting to Generation C. Human Resource Executive.

3. Brown G (2013) The Connected Generation.

4. Nielsen (2012) Introducing Generation C: Americans 18-34 Are the Most Connected.
5. Clear Focus (2013) How to Retain Talent in the Latest Generation C.

6. Friedrich R., Peterson M and Koster A (2011) The Rise of Generation C. Strategy +Business. Spring 62: 1-3.

7. Van Leeuven D (2011) How to prepare for the Connected Generation's transformation of the consumer and business landscape. Tomorrow-Today.

8. Central Intelligence Agency (CIA) (2013) The World Fact Book, People and Society Saudi Arabia.

9. Marshall JM (2002) Learning with Technology: Evidence that technology can and does support learning.

10. Shephard K (2003) Questioning, promoting, and evaluating the use of streaming video to support student learning. Brit J Educ Technol 34: 295-308.

11. Fisch SM (2004) Children's Learning from Educational Television: Sesame Street and beyond. Lawrence Erlbaum Associates. Mahwah. New Jersey.

12. Zhang D, Zhou L, Briggs RO and Nunamaker Jr JF (2006) Instructional video in e-learning: Assessing the impact of interactive video on learning effectiveness. Information \& Management 43: 15-27.

13. Corporation for Public Broadcasting. (2004) Television goes to School: The Impact of Video on Student Learning in Formal Education.

14. Kirkorian HL, Wartella EA and Anderson DR (2008) Media and Young Children's Learning. Children and Electronic Media 18: 39-61.

15. Gulati S (2008) Technology-Enhanced Learning in Developing Nations: A review. The International Review of Research in Open and Distance Learning.

16. Alsajjan B and Dennis C (2010) Internet Banking Acceptance Model: CrossMarket Examination. J Bus Res 63: 1-19.

17. Malshe A, Al-Khatib J, Al-Habib M and Ezzi S (2012) Exploration of SalesMarketing Interface Nuances in Saudi Arabia. J Bus Res 65: 1129-1125.

18. Rice G and Al-Mossawi M (2002) The implications of Islam for advertising messages: Middle Eastern context. Journal of Euromarketing 11: 71-96

19. Hamdan A (2005) Women and education in Saudi Arabia: Challenges and achievements. International Education Journal 6: 42-64.

20. Harden G and Al Beayeyz A (2013) A comparative analysis of social networking site use in two distinct cultures: evaluating the IT-culture conflict. Global Media Journal.

21. Nasr S (1980) The male and female in the Islamic perspective. Studies in Comparative Religion. 14: 1-2.

22. Islahi A (2009) Muslim economic thinking and institutions in the 10th $\mathrm{AH} / 16$ th century. Scientific Publishing Centre King Abdulaziz University Jeddah, Saud Arabia

23. Marshall NM (1996) Sampling for Qualitative Research. Family Practice. Oxford University Press 13: 522-525.

24. Aiken LS and West SG (1991) Multiple Regression: Testing and interpreting interactions. Sage Publication. Newbury Park, CA.

25. Bagozzi RP (1992) Self-regulation of Attitudes, Intentions, and Behavior. Social Psychology Quarterly 55: 178-205.

26. McClelland GH and Judd CM (1993) Statistical difficulties of detecting interactions and moderator effects. Psychological Bulletin 114: 376-390.

27. Escalda LT and Zollman DA (1997) An investigation on the effects of using interactive digital video in a physics classroom on student learning and attitudes. Journal of Research in Science Teaching. 34: 467-489. 